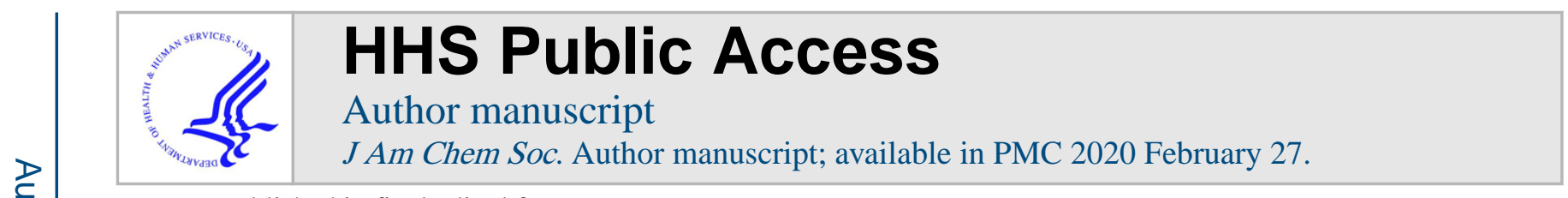

Published in final edited form as:

J Am Chem Soc. 2019 February 27; 141(8): 3430-3434. doi:10.1021/jacs.8b13498.

\title{
Fluorinated Aromatic Monomers as Building Blocks to Control a-Peptoid Conformation and Structure
}

\author{
Diana Gimenez ${ }^{\dagger}$, Guangfeng Zhou ${ }^{\ddagger}$, Matthew F. D. Hurley ${ }^{\ddagger}$, Juan A. Aguilar ${ }^{\dagger}$, Vincent A. \\ Voelz ${ }^{*}, \ddagger$, and Steven L. Cobb ${ }^{*}, \dagger$ \\ †Durham University, Department of Chemistry, South Road, Durham, DH1 3LE, U.K. \\ ‡Temple University, Department of Chemistry, Philadelphia, Pennsylvania 19122, U.S.
}

\begin{abstract}
Peptoids are peptidomimetics of interest in the fields of drug development and biomaterials. However, obtaining stable secondary structures is challenging and designing these requires effective control of the peptoid tertiary amide cis/trans equilibrium. Herein, we report new fluorine containing aromatic monomers that can control peptoid conformation. Specifically, we demonstrate that a fluoropyridine group can be used to circumvent the need for monomer chirality to control the cis/trans equilibrium. We also show that incorporation of a trifluoro-methyl group $\left(N^{\mathrm{CF} 3} \mathrm{Rpe}\right)$ rather than a methyl group ( $\Lambda$ Rpe) at the a-carbon of a monomer gives rise to a 5 -fold increase in cis-isomer preference.
\end{abstract}

\section{Graphical Abstract}

\footnotetext{
*Corresponding Authors: s.l.cobb@durham.ac.uk; voelz@temple.edu. Author Contributions

The manuscript was written with contributions from all authors who have given their approval to the final submitted version. ASSOCIATED CONTENT

Supporting Information

The Supporting Information is available free of charge on the ACS Publications website. This material includes: Experimental procedures and characterization data for peptoid monomers 1, 9-12 and oligomers 13-17 (PDF). X-ray crystallographic data for byproduct from $12(\mathrm{CIF})$
} 


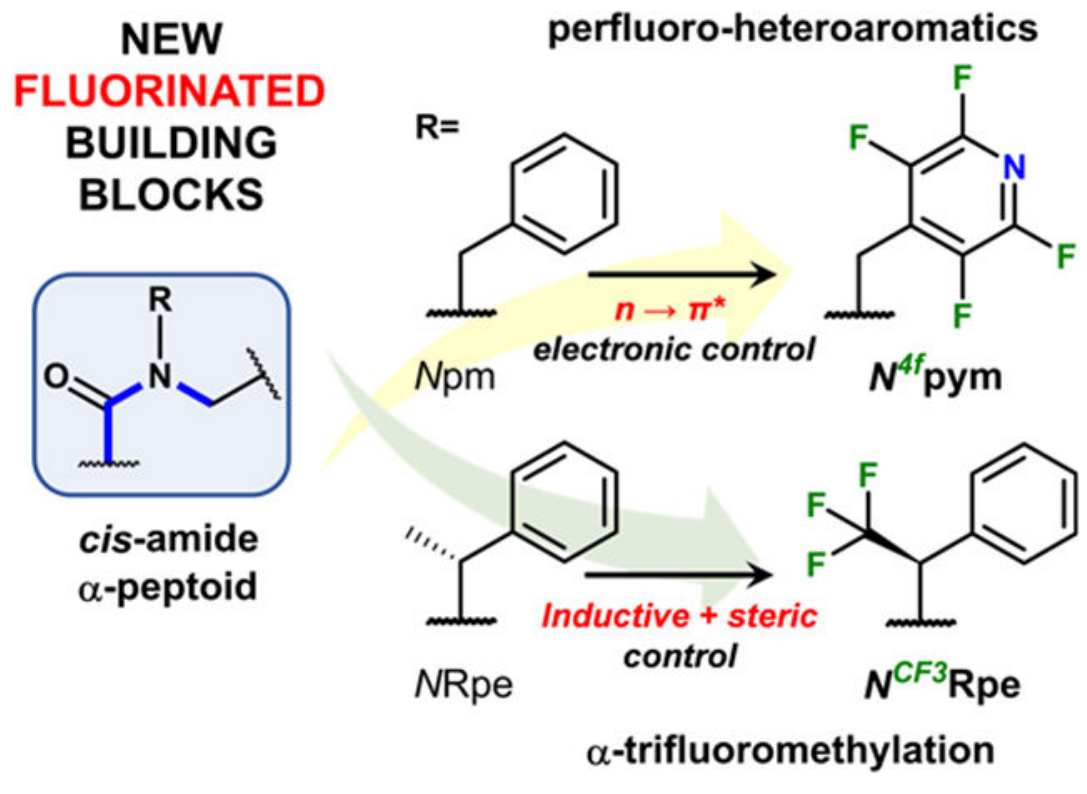

a-Peptoids (Figure 1a) are resistant to protease degradation ${ }^{1}$ and are thermally stable. ${ }^{2}$ They are of interest as therapeutics ${ }^{1,3-8}$ and as biomaterials. ${ }^{9}$ However, because a peptoid is composed of $\mathrm{N}$-alkyl amide bonds, there is no capacity to use hydrogen bonding to stabilize folded structures. Accessing and designing stable structures, such as helices, ${ }^{10-13}$ ribbons, ${ }^{14}$ loops ${ }^{15}$ or sheets ${ }^{16,17}$ relies on utilizing a limited number of peptoid monomers that can predictably restrict the amide bond isomerism. An early advance was reported by Zuckermann and Barron, who showed that monomers with $\mathrm{N}$-a-chiral aromatic sidechains, such as $N$ Spe (2)(Figure 1b), can stabilise all cis-amide polyproline I helices (PPI). ${ }^{10,18}$ Gorske and Blackwell explored non-covalent interactions (NCI) including sterics, hydrogen bonding and electronic $n \longrightarrow \pi^{*}$ effects to control the cis/trans equilibrium in model peptoid systems' through which they identified new chiral peptoid monomers, such as NS1npe (3) and $N$ Sfe (4) (Figure 1b), able to impose larger Kcis/trans values than $N$ Spe (2). ${ }^{19-21}$ Monomers such as $\mathbf{3}$ and $\mathbf{4}$ exert their effects through a synergystic combination of steric factors (e.g. a-methylation) and electronic $n \rightarrow \pi^{*}{ }_{A r}$ interactions. While all of the aforementioned monomers are neutral, pioneering work by Taillefumier and Faure demonstrated that positively charged triazolium-type monomers impart an impressive level of conformational control into a peptoid backbone. ${ }^{22}$ Yet, while this approach gives some of the largest $\mathrm{K}_{\text {cis/trans }}$ values reported, the use of charged monomers puts restrictions on designed peptoid sequences.

While some work has been carried out to exploit fluorine in the design of new peptoid monomers (e.g. NSfe, 4), we sought to investigate the application of perfluoroheteroaromatics, such as tetrafluoropyridine. We hypothesized that such highly electrondeficient systems would favor even stronger $n \longrightarrow \pi^{*} A r$ interactions, overcoming the need for monomer chirality. To investigate this hypothesis, three model di-peptoids based on the nonchiral benzylamine $(N \mathrm{pm}, \mathbf{1})$, pyrinidylmethanamine ( $N$ pym, 9), and (tetrafluoropyrinidyl)methanamine $\left(N^{4 f}\right.$ pym, 10) were prepared for their conformational analysis (Figure 2b). 
We recently reported that fluorine atom(s) $\beta$ to the amide bond nitrogen promote enhanced cis-amide preference in non-chiral alkyl type monomers (Figure 1c). ${ }^{23}$ This cis-amide preference was found to rely on fluorine induced dipolar interactions. Following this we envisaged that incorporation of a trifluoromethyl $\left(\mathrm{CF}_{3}\right)$ group into an aromatic monomer might allow both electronic (dipolar interactions) and steric effects to be utilized in tandem to access systems in which the cis/trans equilibrium completely favors one isomer. To explore this, we prepared the a-trifluoromethyl ( $N^{C F 3}$ Rpe) model peptoid 12 (Figure 2c). For comparison, the non-fluorinated reference $\mathbf{1 1}$ was also prepared. The synthetic route employed to model peptoids $(\mathbf{1 , 9 - 1 2})$ is shown in Figure 2a. ${ }^{20,21}$

We employed ${ }^{1} \mathrm{H}$-NMR and ${ }^{1} \mathrm{H}-{ }^{1} \mathrm{H}$-NOESY to evaluate the cis/trans ratios present within the model systems (see SI for further details). ${ }^{24,20,21}$ Analysis of $\mathbf{1}$ showed that, as reported, the benzyl side-chain induces a solvent dependent conformational preference (Figure 2d). ${ }^{21}$ In $\mathrm{CDCl}_{3}$, a trans-amide geometry by $0.79 \mathrm{kcal} \mathrm{mol}^{-1}$, while in more polar solvents no conformation preference was found (e.g. $\Delta \mathrm{G} \sim 0$ in both $\mathrm{CD}_{3} \mathrm{CN}$ and $\mathrm{CD}_{3} \mathrm{OD}$, Figure $2 \mathrm{~d}$ ). Replacement of the aromatic ring with a hetero-aromatic group caused a significant increase in the cis-isomer preference seen across all of the solvents tested (1 versus $\mathbf{9}$ in Figure 2d). When the electron-withdrawing character of the aromatic ring was further increased, through the incorporation of a tetrafluoropyridine group $\left(N^{4 f}\right.$ pym), an impressive increase in the $\mathrm{K}_{\text {cis/trans }}$ values was seen (10 in Figure 2d and Figure 3). Indeed, 10 showed a 3-fold higher $\mathrm{K}_{\text {cis/trans }}$ value in $\mathrm{CDCl}_{3}$ than its non-fluorinated analogue $\mathbf{9}\left(\mathrm{K}_{\text {cis/trans }}=1.41\right.$ vs. 0.47 , Figure 3). The conformational preference of $\mathbf{1 0}$ was enhanced in polar solvents where highly biased cis-populations were seen $\left(\mathrm{K}\right.$ cis/trans $(\mathrm{CD} 3 \mathrm{CN})=3.22,76 \%$ cis-isomer; $\mathrm{K}_{\text {cis } / \text { trans }}\left(\mathrm{CD}_{3} \mathrm{OD}\right)=$ 2.22, 69\% cis-isomer content; Figure 2d). Interestingly, analysis of the NOE correlations within 10 implied that the fluoro-pyridine ring sits facing the $\mathrm{N}$-terminal carbonyl group in the cis-isomer (Figure 3). This result supports a mechanism in which the cis conformation is stabilized by means of fluorine enhanced $n \rightarrow \pi^{*}{ }_{A r} \mathrm{NCI}$ interactions. The $\mathrm{K}_{\text {cis/trans }}$ values recorded for $\mathbf{1 0}$ are among the highest ever reported for a neutral non-chiral monomer in this type of peptoid model system. What is more remarkable is that despite being a non-chiral monomer, the cis-isomer preferences induced by $N^{4 f}$ pym are comparable or even greater than those produced by the widely utilized $a$-chiral monomers such as $\mathbf{2}$ and $\mathbf{4}$ (Figure 2b and Figure 2d).

We then turned our attention to effects imparted by fluorine at the a-methyl position. The results obtained for the reference (11) agreed fully with those previously reported for the (S)-enantiomer (NSpe, 2) (Figure 2d). ${ }^{21} 11$ exhibited almost no conformational preference in $\mathrm{CDCl}_{3}\left(\mathrm{~K}_{\text {cis/trans }} \sim 1.0\right)$. Again, in line with the literature, in polar solvents its cis/trans equilibrium shifted in favour of the cis-isomer, particularly in $\mathrm{MeCN}\left(\mathrm{Kcis} /\right.$ trans= 2.07) ${ }^{21}$

In stark contrast, however, the $N^{C F}$ Rpe containing di-peptoid 12 displayed a high degree of conformational preference. Both the ${ }^{1} \mathrm{H}$ and the ${ }^{19} \mathrm{~F}$ NMR data of $\mathbf{1 2}$ revealed the presence of one isomer in solution with a predominance of $284 \%$ (Figure 2d). It was not possible to use ${ }^{1} \mathrm{H}-{ }^{1} \mathrm{H}$ NOESY correlations within 12 to assign the configuration of the major isomer present (e.g see Fig. S95). Therefore, to better understand the conformational preference exhibited by 12, computational studies were performed using both ab initio QM and replica exchange molecular dynamics (REMD). 
Scans of side-chain and backbone dihedral angles were performed using DFT at the B3LYP/6-311G+(2d,p)//HF/6-31G(p) level of theory (Figure 4). To identify side-chain conformational minima, $\chi_{1}$ and $\chi_{2}$ angles were first scanned from $0^{\circ}$ to $360^{\circ}$ in $30^{\circ}$ intervals starting from typical backbone conformations of peptoids: cis-amide $\mathrm{a}_{\mathrm{D}}(\varphi, \psi=$ $\left.-90^{\circ}, 180^{\circ}\right)$, trans-amide $a_{D}\left(\varphi, \psi=-90^{\circ}, 180^{\circ}\right)$, and trans-amide $C_{7 \beta}\left(\varphi, \psi=-130^{\circ}, 80^{\circ}\right)$, with all remaining dihedral angles unrestrained during geometry optimization (Figure $4 \mathrm{~b}$, Fig. S115). The results showed a preference for $\chi_{1}, \chi_{2}$ near $\left(-90^{\circ},+15^{\circ}\right)$ in cis-amide structures, and a mixture of $\left(-90^{\circ},+15^{\circ}\right)$ and $\left(+90^{\circ},+15^{\circ}\right)$ preferences in trans-amide structures, consistent with similar work for related molecules. ${ }^{25}$ Next, full backbone dihedral scans of $\varphi$ and $\psi$ angles ( $15^{\circ}$ intervals) were performed starting from cis-amide and transamide isomers with $90^{\circ}$ and $+90^{\circ} \chi_{1}$ angles, with all dihedral angles except $\varphi$ and $\psi$ unrestrained during optimization (Fig. S116). From these studies, the cis-amide energy minimum was found to be $1.26 \mathrm{kcal} \mathrm{mol}^{-1}$ lower than the trans-amide, in excellent agreement with the experimental $\mathrm{K}_{\text {cis/trans }}$ values measured (Figure $2 \mathrm{~d}$ ). In comparison, similar calculations for $N$ Spe show a cis/trans energy minima gap of only $0.2 \mathrm{kcal} \mathrm{mol}^{-1} .^{26}$ These results, in combination with the experiments above, strongly indicated that the single isomer seen experimentally corresponded to the cis-amide conformation.

The computed backbone dihedral $(\varphi, \psi)$ landscape of $\mathbf{1 2}$ resembles that of the NSpe monomer, ${ }^{25,26}$ but unlike $N$ Spe, which favors a negative backbone $\varphi$-angle (near $-90^{\circ}$ ) by $\sim 1 \mathrm{kcal} \mathrm{mol}^{-1}$ over the positive angle (near $+90^{\circ}$ ), 12 favors the positive angle by $\sim 0.8 \mathrm{kcal}$ mol $^{-1}$ (Fig. S116). This may partly be due to unfavorable proximity (3.1 $\AA$ ) of the carbonyl oxygen to the nearest fluorine in the electronegative $\mathrm{CF}_{3}$ group for the cis-amide negative $\varphi$ angle conformation ( $5.2 \AA$ for the positive $\varphi$-angle conformation).

Comparative analysis of model systems 1, 9, 10, 11 and 12 using natural bond orbital (NBO) analysis (see SI for details) suggests the presence of $n \rightarrow \pi^{*}$ effects, as seen by a decrease in the natural charge of the carbonyl oxygen atom and increase in the total $\pi^{*}$ occupancy of the aromatic system. The extent of these effects is strongly correlated with the experimental $\mathrm{K}_{\text {cis/trans }}$ ratios, and are most significant for system 10. These effects are less significant for system 12, supporting a mechanism of cis-isomer stabilization in $\mathbf{1 2}$ in which a combination of inductive and steric factors, rather than $n \longrightarrow \pi^{*}$ interactions per se, act to achieve such a large $\mathrm{K}_{\text {cis/trans }}$ ratio. This result also agrees with the orientation of the carbonyl and aromatic groups in the minimum energy structure of $\mathbf{1 2}$.

To predict the conformational preferences of $N^{C F 3}$ Rpe oligomers, we performed replica exchange molecular dynamics (REMD) simulations ${ }^{26,27}$ of $\mathbf{1 2}$ as well as the related oligomeric species Ac-[ ${ }^{C F} 3$ Rpe $] n$-Pip, for $n=1,2,3,4,5$. (Figure 4c). The simulations agreed with QM studies (Table S6), with cis-amide populations above 95\% for all residues (Fig. S117). Strikingly, simulations also predicted that larger oligomers are increasingly prone to form stable right-handed helices (e.g. negative $\varphi$-angle), with $N^{C F 3}$ Rpe pentamers displaying cis-amide helix populations of nearly $100 \%$ (Figure 4c-h). These results likely stem from the large $\mathrm{K}_{\text {cis/trans }}$ value for $\mathbf{1 2}$, which is additionally rewarded by the excellent side-chain packing achieved in the helical conformation. The difference between the $\varphi$-angles seen in the model (12) and the $N^{C F 3}$ Rpe oligomers we believe arise due to 12 being unconstrained by the side chain packing that is present within the oligomers. ${ }^{12,14}$ 
The REMD simulations were experimentally validated by ${ }^{19}$ F-NMR (Figure 5a; Fig. S126) and circular dichroism (CD) (Figure 5a; Fig. S140) analysis of oligomers 13-15. By comparison of $\mathbf{1 3}$ and $\mathbf{1 4}$ it can be seen that increasing the number of sequential $N^{C F 3}$ Rpe residues leads to an increase in the conformational homogeneity.. Similarly, removal of ${ }^{C}{ }^{C F 3}$ Rpe residues from the sequence (e.g. 14 versus 15) leads to a decrease in conformational homogeneity. In addition, HSQC-TOCSY and NOESY analysis of peptoid 14 demonstrated the enhanced cis-amide preference of the $N^{C F 3}$ Rpe residues (Kcis/trans= 2.3) compared to the $N$ Spe $\left(\mathrm{K}_{\text {cis/trans }}=0.7\right)$ (Figure 5b; Figs. S127 and S130). To further explore the application of $N^{C F 3}$ Rpe as a tool to stabilize the helical conformation of longer peptoids two model heterooligomers were prepared (16 and 17, Figure $5 \mathrm{c}$ ).

When the secondary structures of $\mathbf{1 6}$ and $\mathbf{1 7}$ were analyzed by CD clear differences beyond the opposing helical chirality enforced by both monomers (e.g. left-hand helix for $N$ Rpe and a right-handed helix for $N^{C F 3}$ Rpe) were seen. Specifically, 17 showed a dramatic $42 \%$ increase in the $\mathrm{M}_{\theta, 218}$ compared to 16. This result provides clear evidence that the substitution of non-fluorinated $N$ Re residues by their a-trifluoromethyl analogues $\left(N^{C F 3} \mathrm{Rpe}\right)$ offers a route to enhance the peptoid secondary helical structure.

In summary, we report the application of fluorine as a tool to design monomers which enhance the conformational stability of a-peptoids. The Kcis/trans values recorded for the $N^{4 f}$ pym containing di-peptoid $\mathbf{1 0}$ are among the largest ever reported for a non-chiral monomer. $N^{4 f}$ pym also represents the first example of a non-chiral, non-charged aromatic monomer that can induce a strong cis-amide preference. The $N^{4 f}$ pym residue achieves its high $\mathrm{K}_{\text {cis/trans }}$ values by pushing the electronic $n \rightarrow \pi^{*}$ effects to the limit of what is possible in a neutral system. We recently reported the application of fluorine inductive/ di-polar effects as a new tool to modulate Kcis/trans ratios $^{23}$ but the $N^{C F 3}$ Rpe monomer presented here demonstrate the benefits of combining fluorine induced steric and fluorine induced inductive electronic effects. Indeed, as evidenced by NMR analysis, ab initio and molecular dynamics calculations, the $N^{C F 3}$ Rpe monomer has the ability to push the Kcis/trans equilibrium to essentially favor one single isomer. REMD simulations of $N^{C F 3}$ Rpe oligomers predicted the formation of highly stable righthanded helices and this was experimentally validated via preparation and subsequent conformational analysis of a series of $N^{C F 3}$ Rpe containing peptoid oligomers. $N^{4 f}$ pym and $N^{C F 3}$ Rpe provide a much-needed expansion of the limited tool-box of monomers currently available for the rational design of conformationally stable peptoids.

\section{Supplementary Material}

Refer to Web version on PubMed Central for supplementary material.

\section{ACKNOWLEDGMENTS}

We thank Graham E. Dobereiner for expertise with Natural Bond Orbital calculations. This work was financially supported by the Initial Training Network, FLUOR21, funded by the FP7 Marie Curie Actions of the European Commission (FP7-PEOPLE-2013-ITN-607787). In addition, V.A.V., G.Z. and M.H. were supported by National Institutes of Health (NIH) grant 1R01GM123296. This research includes calculations performed on Temple University's HPC resources partially supported by the National Science Foundation through MRI grant 1625061 and by the US Army Research Laboratory under contract number W911NF-16-2-0189. 


\section{REFERENCES}

(1). Luo Y; Bolt HL; Eggimann GA; McAuley DF; McMullan R; Curran T; Zhou M; Jahoda PCAB; Cobb SL; Lundy FT Peptoid Efficacy against Polymicrobial Biofilms Determined by Using Propidium Monoazide-Modified Quantitative PCR. ChemBioChem 2017, 18 (1), 111-118 [PubMed: 27900840]

(2). Sanborn TJ; Wu CW; Zuckermann RN; Barron AE Extreme stability of helices formed by watersoluble poly-N-substituted glycines (polypeptoids) with a-chiral side chains. Biopolymers 2002, 63 (1), 12-20. [PubMed: 11754344]

(3). Eggimann GA; Bolt HL; Denny PW; Cobb SL Investigating the Anti-leishmanial Effects of Linear Peptoids. ChemMedChem 2015, 10 (2), 233-237 [PubMed: 25512204]

(4). Chongsiriwatana NP; Patch JA; Czyzewski AM; Dohm MT; Ivankin A; Gidalevitz D; Zuckermann $\mathrm{RN}$; Barron AE Peptoids that mimic the structure, function, and mechanism of helical antimicrobial peptides. Proc. Natl. Acad. Sci 2008, 105 (8), 2794-2799. [PubMed: 18287037]

(5). Hara T; Durell SR; Myers MC; Appella DH Probing the Structural Requirements of Peptoids That Inhibit HDM2-p53 Interactions. J. Am. Chem. Soc 2006, 128 (6), 1995-2004. [PubMed: 16464101]

(6). Trader DJ; Simanski S; Kodadek T A Reversible and Highly Selective Inhibitor of the Proteasomal Ubiquitin Receptor Rpn13 Is Toxic to Multiple Myeloma Cells. J. Am. Chem. Soc 2015, 137 (19), 6312-6319. [PubMed: 25914958]

(7). Reddy MM; Wilson R; Wilson J; Connell S; Gocke A; Hynan L; German D; Kodadek T Identification of Candidate IgG Biomarkers for Alzheimer's Disease via Combinatorial Library Screening. Cell 2011, 144 (1), 132-142. [PubMed: 21215375]

(8). Zhao Z; Zhu L; Bu X; Ma H; Yang S; Yang Y; Hu Z Label-free detection of Alzheimer's disease through the ADP3 peptoid recognizing the serum amyloid-beta42 peptide. Chem Commun 2015, $51(4), 718-721$.

(9). (a) Lee B-C; Chu TK; Dill KA; Zuckermann RN Biomimetic Nanostructures: Creating a HighAffinity Zinc-Binding Site in a Folded Nonbiological Polymer. J. Am. Chem. Soc 2008, 130 (27), 8847-8855. [PubMed: 18597438] (b)Reddy MM; Kodadek T Protein "fingerprinting" in complex mixtures with peptoid microarrays. Proc. Natl. Acad. Sci. U. S. A 2005, 102 (36), 12672-12677. [PubMed: 16123137] (c)Knight AS; Zhou EY; Pelton JG; Francis MB Selective Chromium(VI) Ligands Identified Using Combinatorial Peptoid Libraries. J. Am. Chem. Soc 2013, 135(46), 17488-17493. [PubMed: 24195610] (c)Baskin M; Maayan G A rationally designed metal-binding helical peptoid for selective recognition processes. Chem Sci. 2016, 7 (4), 2809-2820. [PubMed: 28660058] (d)Pirrung MC; Park K; Tumey LN ${ }^{19}$ F-Encoded Combinatorial Libraries: Discovery of Selective Metal Binding and Catalytic Peptoids. J. Comb. Chem 2002, 4 (4), 329-344 [PubMed: 12099851] (e)Maayan G; Ward MD; Kirshenbaum K Folded biomimetic oligomers for enantioselective catalysis. Proc. Natl. Acad. Sci 2009, 106 (33), 13679-13684. [PubMed: 19667204]

(10). Armand P; Kirshenbaum K; Goldsmith RA; Farr-Jones S; Barron AE; Truong KT; Dill KA; Mierke DF; Cohen FE; Zuckermann RN; Bradley EK NMR determination of the major solution conformation of a peptoid pentamer with chiral side chains. Proc. Natl. Acad. Sci 1998, 95 (8), 4309-4314. [PubMed: 9539733]

(11). Murnen HK; Rosales AM; Jaworski JN; Segalman RA; Zuckermann RN Hierarchical SelfAssembly of a Biomimetic Diblock Copolypeptoid into Homochiral Superhelices. J. Am. Chem. Soc 2010, 132 (45), 16112-16119. [PubMed: 20964429]

(12). Stringer JR; Crapster JA; Guzei IA; Blackwell HE Extraordinarily Robust Polyproline Type I Peptoid Helices Generated via the Incorporation of a-Chiral Aromatic N-1-Naphthylethyl Side Chains. J. Am. Chem. Soc 2011, 133 (39), 15559-15567. [PubMed: 21861531]

(13). (a) Gorske BC; Mumford EM; Gerrity CG; Ko I A Peptoid Square Helix via Synergistic Control of Backbone Dihedral Angles. J. Am. Chem. Soc 2017, 139 (24), 8070-8073. [PubMed: 28537738] (b)Roy O; Dumonteil G; Faure S; Jouffret L, Kriznik A; Taillefumier C Highly homogeneous and robust PolyProline type I helices from peptoids with non-aromatic a-chiral side chains. J. Am. Chem. Soc 2017, 139 (38), 13533-13540. [PubMed: 28837348] 
(14). Crapster JA; Guzei IA; Blackwell HE A Peptoid Ribbon Secondary Structure. Angew. Chem. Int. Ed 2013, 52 (19), 5079-5084.

(15). Huang K; Wu CW; Sanborn TJ; Patch JA; Kirshenbaum K; Zuckermann RN; Barron AE; Radhakrishnan I A Threaded Loop Conformation Adopted by a Family of Peptoid Nonamers. J. Am. Chem. Soc 2006, 128 (5), 1733-1738. [PubMed: 16448149]

(16). Mannige RV; Haxton TK; Proulx C; Robertson EJ; Battigelli A; Butterfoss GL; Zuckermann RN; Whitelam S Peptoid nanosheets exhibit a new secondary-structure motif. Nature 2015, 526 (7573), 415-420. [PubMed: 26444241]

(17). Nam KT; Shelby SA; Choi PH; Marciel AB; Chen R; Tan L; Chu TK; Mesch RA; Lee B-C; Connolly MD; Kisielowski C; Zuckermann RN Free-floating ultrathin two-dimensional crystals from sequence-specific peptoid polymers. Nat. Mater. 2010, 9 (5), 454-460. [PubMed: 20383129]

(18). Armand P; Kirshenbaum K; Falicov A; Dunbrack RL; Dill KA; Zuckermann RN; Cohen FE Chiral N-substituted glycines can form stable helical conformations. Fold. Des 1997, 2 (6), 369375. [PubMed: 9427011]

(19). Gorske BC; Blackwell HE Tuning Peptoid Secondary Structure with Pentafluoroaromatic Functionality: A New Design Paradigm for the Construction of Discretely Folded Peptoid Structures. J. Am. Chem. Soc 2006, 128 (44), 14378-14387. [PubMed: 17076512]

(20). Gorske BC; Bastian BL; Geske GD; Blackwell HE Local and Tunable $n \rightarrow \pi^{*}$ Interactions Regulate Amide Isomerism in the Peptoid Backbone. J. Am. Chem. Soc 2007, 129 (29), 89288929. [PubMed: 17608423]

(21). Gorske BC; Stringer JR; Bastian BL; Fowler SA; Blackwell HE New Strategies for the Design of Folded Peptoids Revealed by a Survey of Noncovalent Interactions in Model Systems. J. Am. Chem. Soc 2009, 131 (45), 16555-16567. [PubMed: 19860427]

(22). Aliouat H; Caumes C; Roy O; Zouikri M; Taillefumier C; Faure S 1,2,3-Triazolium-Based Peptoid Oligomers. J. Org. Chem 2017, 82 (5), 2386-2398. [PubMed: 28225627]

(23). Gimenez D; Aguilar JA; Bromley EHC; Cobb SL Angew. Chem. Int. Ed 2018, 57 (33), 10549_ 10553.

(24). Sui Q; Borchardt D; Rabenstein DL Kinetics and Equilibria of Cis/Trans Isomerization of Backbone Amide Bonds in Peptoids. J. Am. Chem. Soc 2007, 129 (39), 12042-12048. [PubMed: 17824612]

(25). Butterfoss GL; Renfrew PD; Kuhlman B; Kirshenbaum K; Bonneau R A Preliminary Survey of the Peptoid Folding Landscape. J. Am. Chem. Soc 2009, 131 (46), 16798-16807. [PubMed: 19919145]

(26). Mukherjee S; Zhou G; Michel C; Voelz VA Insights into Peptoid Helix Folding Cooperativity from an Improved Backbone Potential. J. Phys. Chem. B 2015, 119 (50), 15407-15417. [PubMed: 26584227]

(27). Voelz VA; Dill KA; Chorny I Peptoid conformational free energy landscapes from implicitsolvent molecular simulations in AMBER. Biopoly-mers 2011, 96 (5), 639-650. 
a)

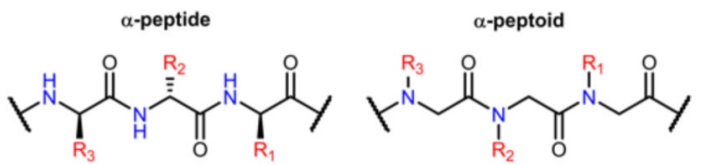

b)

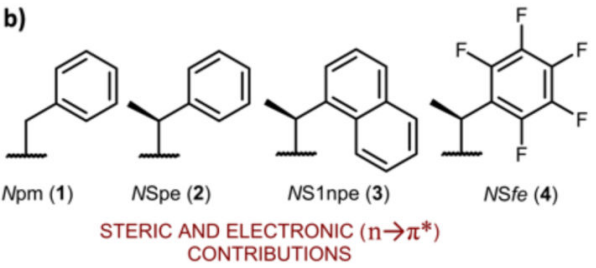

d)

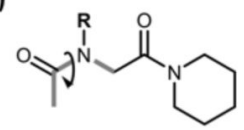

c)

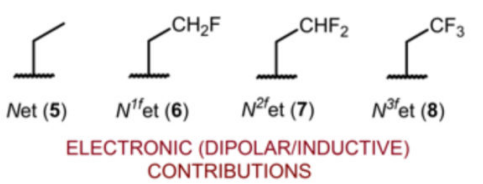

$R=(1) K_{\text {cistrans }}=0.62 \quad R=(5) K_{\text {cistrans }}=0.51$

$R=(2) K_{\text {cistrans }}=1.26 \quad R=(6) K_{\text {cistrans }}=0.74$

$\mathrm{R}=(3) \mathrm{K}_{\text {cistrans }}=4.63 \quad \mathrm{R}=(\mathbf{7}) \mathrm{K}_{\text {cistrans }}=1.17$

$R=(4) K_{\text {cistrans }}=2.46 \quad R=(8) K_{\text {cistrans }}=1.23$

CONTRIBUTIONS

e)

via
perfluoro-heteroaromatics

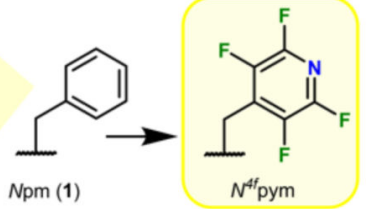

Enhancing cis-amide preference

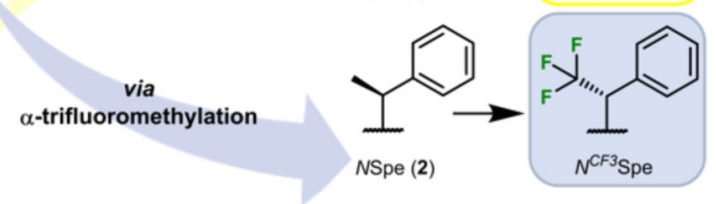

Figure 1.

a) a-peptides and a-peptoids; b) cis-amide preference due to steric and $n \longrightarrow \pi$ electronic effects (2-4); c) cis-amide preference due to inductive effects (5-8); d) $\mathrm{K}_{\text {cis/trans }}\left(\mathrm{CD}_{3} \mathrm{OD}\right)$ for monomers 1-8; e) Application of fluorine to enhance cis-isomer preference. 

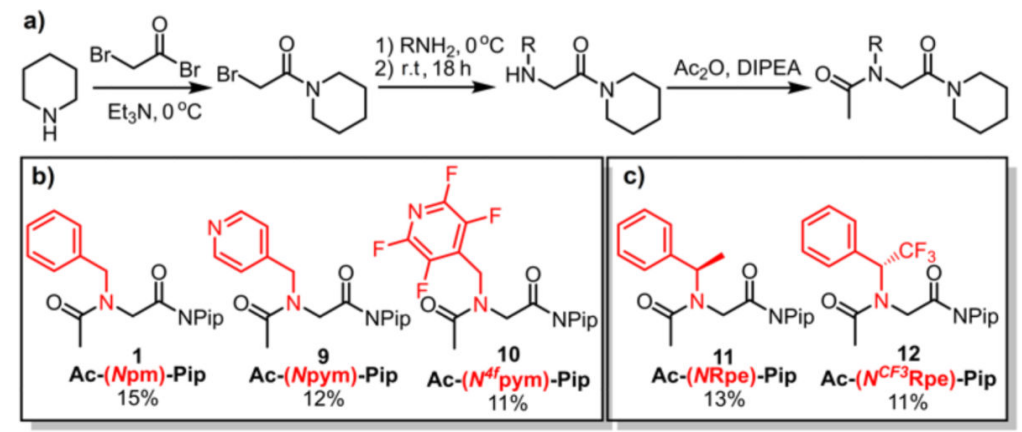

\begin{tabular}{|c|c|c|c|c|c|c|}
\hline \multirow{2}{*}{$\begin{array}{l}\text { d) } \\
\text { Product }\end{array}$} & \multicolumn{2}{|c|}{$\left(\mathrm{CDCl}_{3}\right)$} & \multicolumn{2}{|c|}{$\left(\mathrm{CD}_{3} \mathrm{CN}\right)$} & \multicolumn{2}{|c|}{$\left(\mathrm{CD}_{3} \mathrm{OD}\right)$} \\
\hline & $\mathrm{K}_{\text {cis/trans }}$ & $\begin{array}{r}\mathrm{AVG}_{\Delta} \Delta \mathrm{G}_{\text {cis/rans }} \\
\left(\mathrm{kcal} \mathrm{mol}^{-1}\right)\end{array}$ & $\mathrm{K}_{\text {cis/trans }}$ & $\begin{array}{r}{ }^{\mathrm{AVG}} \Delta \mathrm{G}_{\text {cistrans }} \\
\left(\mathrm{kcal} \mathrm{mol}^{-1}\right)\end{array}$ & $\mathrm{K}_{\text {cis/trans }}$ & $\begin{array}{r}{ }^{A V G} \Delta G_{\text {cistrans }} \\
\left(\mathrm{kcal} \mathrm{mol}^{-1}\right)\end{array}$ \\
\hline 1 & $0.27 \pm 0.01$ & $0.79 \pm 0.03$ & $1.20 \pm 0.06$ & $-0.11 \pm 0.03$ & $0.71 \pm 0.03^{[\mathrm{a}]}$ & $0.20 \pm 0.03^{[a]}$ \\
\hline 9 & $0.46 \pm 0.01$ & $0.45 \pm 0.02$ & $1.66 \pm 0.06$ & $-0.30 \pm 0.02$ & $1.15 \pm 0.02$ & $-0.08 \pm 0.01$ \\
\hline 10 & $1.41 \pm 0.16$ & $-0.20 \pm 0.08$ & $3.22 \pm 0.12$ & $-0.69 \pm 0.03$ & $2.22 \pm 0.04$ & $-0.47 \pm 0.01$ \\
\hline 11 & $0.92 \pm 0.05$ & $0.05 \pm 0.04$ & $2.07 \pm 0.12$ & $-0.43 \pm 0.04$ & $1.35 \pm 0.04$ & $-0.18 \pm 0.02$ \\
\hline $12^{[\mathrm{b}][\mathrm{c}]}$ & $5.17 \pm 1.25$ & $-0.95 \pm 0.19$ & $5.82 \pm 0.23$ & $-1.04 \pm 0.03$ & $6.41 \pm 0.13$ & $-1.10 \pm 0.02$ \\
\hline
\end{tabular}

Figure 2.

a) Synthesis of model peptoids; b) Non-chiral di-peptoids 1, 9-10; c) Chiral di-peptoids 11, 12. d) Average $\mathrm{K}_{\text {cis/trans }}$ values for 1, 9-12. From each replica, $\Delta G=-\mathrm{RTLn}\left(\mathrm{K}_{\text {cis/trans }}\right)$ at $25^{\circ} \mathrm{C}$. Averages and SD values given for $n=6$; ${ }^{[a]} n=5$ and ${ }^{[b]} n=3$. ${ }^{[c]}$ Major isomer assigned as cis, in agreement with MD data. 
a)

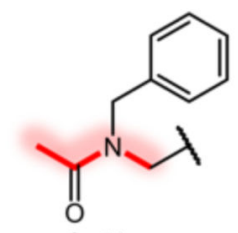

1, Npm

$\mathrm{K}_{\text {cis/trans }}=$

0.27

$\Delta \mathrm{G}_{\text {cis/trans }}=0.79$

b)

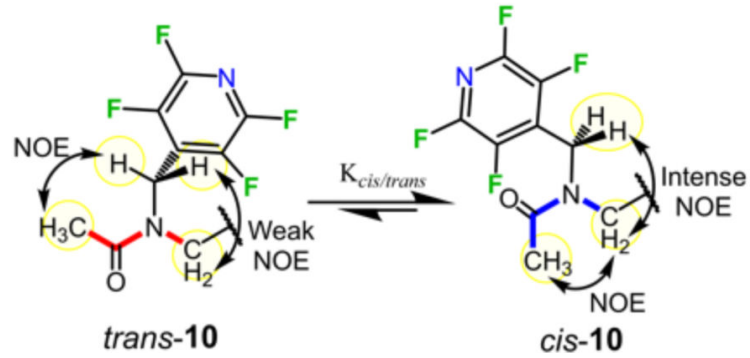

Figure 3.

a) Amide bond geometry in systems 1,9 and 10. b) Experimental ${ }^{1} \mathrm{H}-{ }^{1} \mathrm{H}$ NOESY correlations within cis/trans conformers of 10. All Kcis/trans values as determined in $\mathrm{CDCl} 3$. 
a)

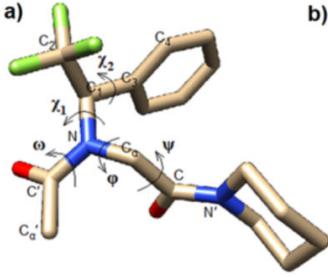

c)

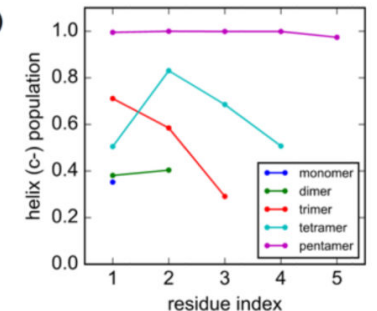

\begin{tabular}{ccccc}
\hline \multicolumn{4}{c}{ initial } & \multicolumn{3}{c}{ final } \\
\hline$\omega$ & $\mathbf{X}_{1}$ & $\boldsymbol{\omega}$ & $\mathbf{X}_{1}$ & $\begin{array}{c}\text { Energy } \\
\text { minimum } \\
\left(\mathbf{k c a l ~ m o l}^{-1}\right)\end{array}$ \\
\hline $0^{\circ}$ (cis) & $-90^{\circ}$ & $11.2^{\circ}$ & $-85.4^{\circ}$ & 0.00 \\
$0^{\circ}$ (cis) & $+90^{\circ}$ & $9.1^{\circ}$ & $92.3^{\circ}$ & 4.66 \\
$180^{\circ}$ (trans) & $-90^{\circ}$ & $-173.0^{\circ}$ & $-82.9^{\circ}$ & 1.26 \\
$180^{\circ}$ (trans) & $+90^{\circ}$ & $-173.8^{\circ}$ & $87.7^{\circ}$ & 2.50 \\
\hline
\end{tabular}

d)

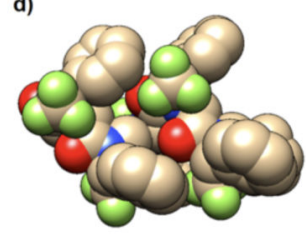

e)

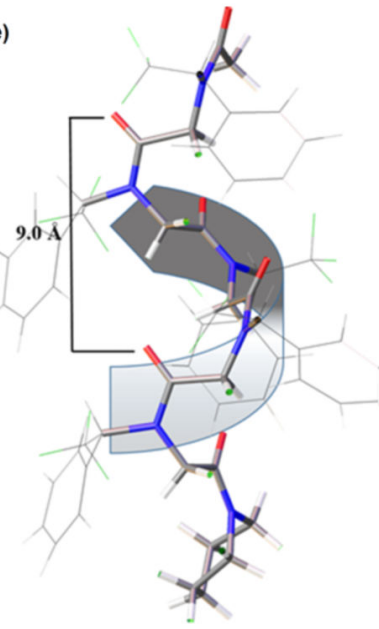

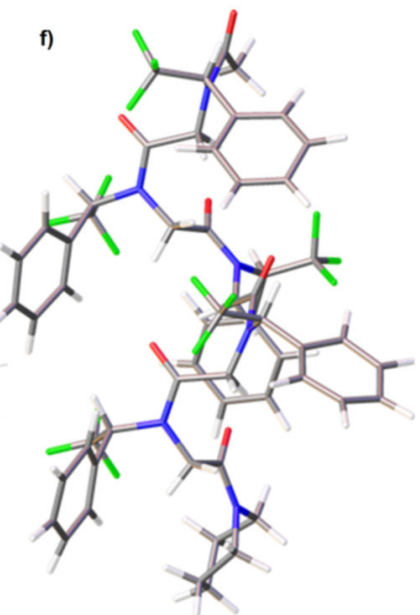

Figure 4.

a) The lowest-energy conformation of $\mathbf{1 2}$, annotated with dihedral angle definitions (see SI for details). b) Lowest-energy minima found in $\varphi, \psi$ backbone dihedral scans started from cis- and trans-amide conformations with side-chain orientations $\chi 1=-9^{\circ}$ and $+90^{\circ}$. c) REMD simulations of oligomeric analogues of 12, Ac- $\left[N^{C F}{ }^{R} \text { Rpe }\right]_{n}$-Pip $(n=1,2,3,4,5)$ showing an increasing preference to form right-handed cis-amide helices. d) Space-filling model of the predicted pentamer structure $(n=5)$. e-f) Longitudinal views of a representative frame of the oligomer from the lowest temperature replica (300 K). 
a)

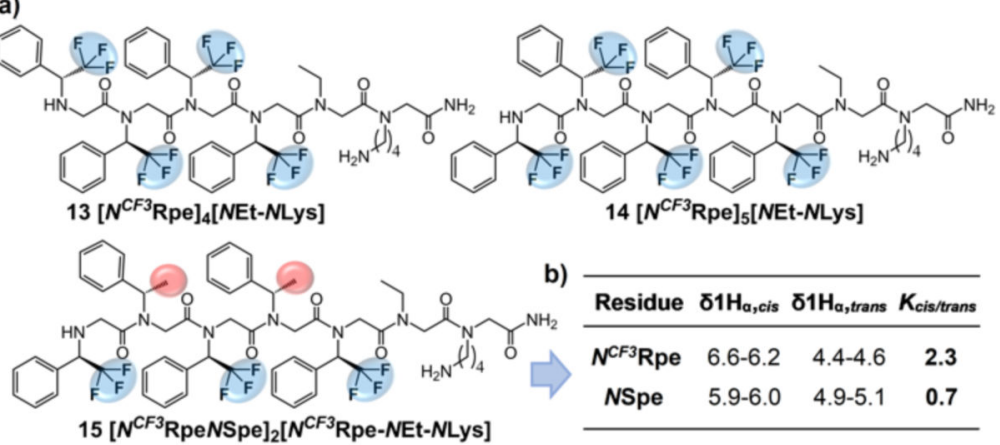

c)

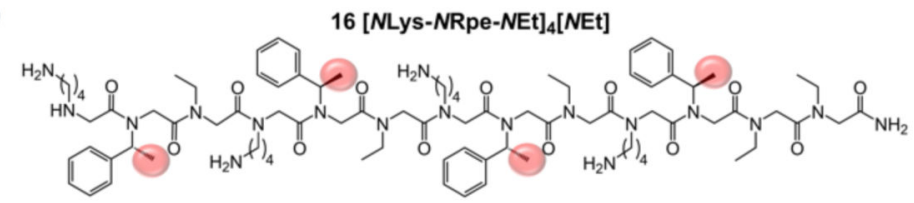

17 [NLys- $\left.N^{\text {CF }}{ }^{\text {Rpe-NEt }}\right]_{4}[N E t]$
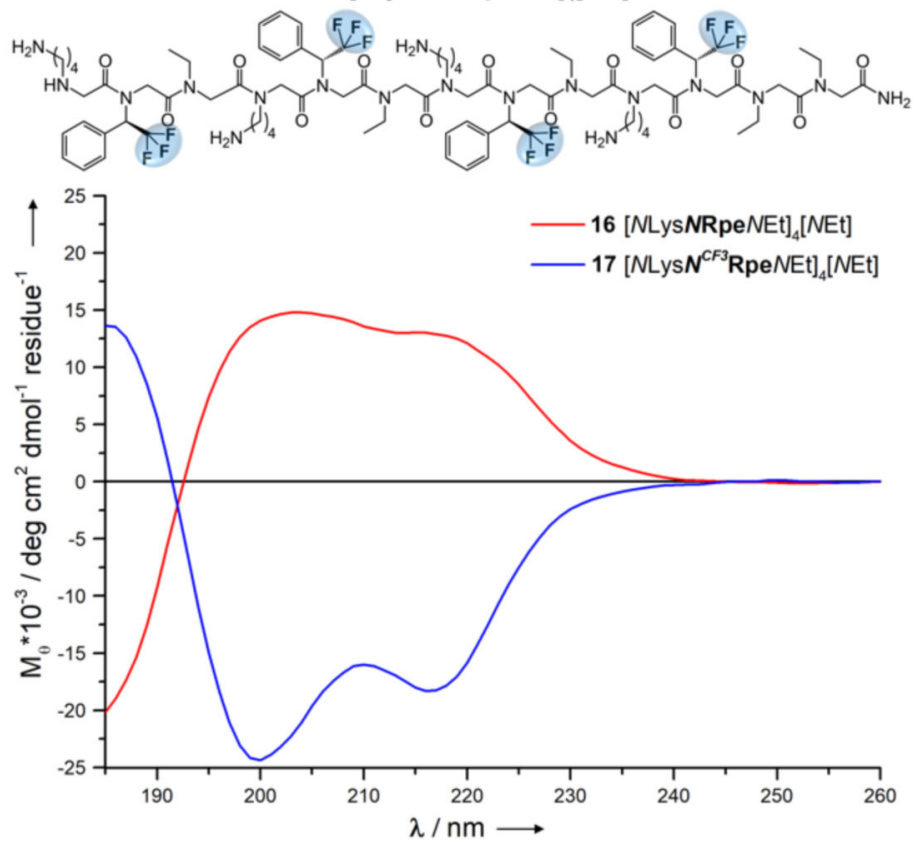

Figure 5.

a) Structure of peptoid oligomers 13-15. b) Main ${ }^{1} \mathrm{H}-\mathrm{NMR}$ parameters of $\mathrm{NSpe}$ and $N^{C F 3}$ Rpe residues as analyzed in 15 . c) Structure and average CD spectra $(n=3)$ of peptoid hetero-oligomers $\mathbf{1 3}$ (shown in red) and $\mathbf{1 4}$ (shown in blue). All measurements in MeCN. 